\title{
E-LEARNING FOR THE VISION IMPAIRED: A HOLISTIC
}

\section{PERSPECTIVE}

\author{
Ruchi Permvattana \\ Curtin University \\ GPO Box U1987, Perth, Australia 6845 \\ ruchireak.permvattana@student.curtin.edu.au \\ Helen Armstrong \\ Curtin University \\ GPO Box U1987, Perth, Australia 6845 \\ h.armstrong@curtin.edu.au \\ Iain Murray \\ Curtin University \\ GPO Box U1987, Perth, Australia 6845 \\ i.murray@curtin.edu.au
}

\begin{abstract}
Problems faced by vision impaired students are different from those experienced by sighted students. Most e-learning environments are designed for sighted students, utilizing complex visual images and interactive features; however students with acute vision impairments are not able to utilize these features and must rely on applications to translate the contents of screen displays and documents into forms that are accessible. Learning environments for people with physical disabilities need specific considerations in design and implementation to ensure their appropriateness and accessibility. This paper initially discusses specific problems faced by students with acute vision impairments and
\end{abstract}


how e-learning environments need to address these problems in order for the student to achieve the same learning outcomes as sighted students. A brief outline of the research method is followed by a description of the holistic model proposed for accessible e-learning environment design.

Keywords: E-learning, Vision Impaired, Accessibility

\section{INTRODUCTION}

The use of the Internet is an integral tool for communication in the twenty first century; however there are many people with vision impairments who need to learn specific skills in order to take advantage of this tool. Such people have previously been disadvantaged due to inaccessible learning materials or instructional media which have not been tailored to their specific needs. Generally, people who have acute vision disabilities find it difficult to obtain suitable employment. This results in low income and in turn affects their quality of life. Numerous research projects report low achievement at secondary and tertiary levels for the vision impaired and this is often the result of a lack of accessibility of the learning materials in addition to a lack of knowledge and understanding of disabilities by the teaching staff (Dept Finance, 2010). Figures produced by the Australian Bureau of Statistics (ABS, 2009) demonstrate that there is a significant difference between educational achievement and employment income between those with a disability and those without. Four million people in Australia (18.5\%) reported having a disability according to the results of the Survey of Disability, Ageing and Carers. Vision Australia (2007) reports that $63 \%$ of people who are blind or vision impaired and who are of working age are unemployed. Education is a vital factor in preparing students to develop into responsible adults who can take their place in the work force. It is therefore important that those with vision impairments are able to access as complete an education as possible so that they can gain useful employment and participate constructively in society.

For all students, vision is the primary sense necessary for successful learning and development (Kelly et al., 2000). One of the main difficulties caused by visual impairment is the problem of access to information, and with the developing use of technology this difficulty is increasing (Armstrong et al., 2010). Without vision, students and teachers use speech to a much greater extent and a virtual classroom is needed to 
supplement the physical classroom and laboratory setting.

\section{ACCESSIBILITY AND STUDENTS}

\section{Nature of Blindness}

Vision impairment relates to those students who are categorized as legally blind, having a visual acuity of 6/60 or less in the better eye, and/or a visual field of less than 10 degrees (Retina Australia, 2012). The vision impaired students investigated have either been blind since birth or have lost their sight due to illness or medication. As there are many causes of blindness, the circumstances of each student need to be understood before the problems they face can be addressed. In addition, students who are totally blind will have different needs from those who have a small amount of vision. Limited vision can also take many forms including differentiating between dark and light, tunnel vision or having only peripheral vision. Each student has a different set of circumstances relating to their disability, and e-learning environments need to take into consideration the limitations posed by these circumstances. Vision impaired students need tools to enable them to use computers. Screen readers are used to translate text to audio for those students who are totally blind, and screen magnifiers enlarge text and objects on the screen display for those students who have a small amount of usable vision. Screen reading software is designed specifically to translate text into audio, and features beyond this are limited. Instructional designers need to be mindful of accessibility issues for screen readers to be able to translate accurately.

\section{Problems Faced by Vision Impaired Students}

Some of the most common problems faced by students with acute vision impairment include inaccessibility of Web sites, inaccessibility of learning materials and different learning needs due to their disabilities. One of the most prominent problems is that e-learning IT courses are not specifically designed for vision impaired students. The guidelines for Web accessibility for the vision impaired are not specific enough for the effective design of learning materials for the vision impaired. There is also a misalignment of guidelines for the development of accessible teaching and learning materials and Web accessibility standards and guidelines. Additional teaching aids created specifically for vision impaired students are necessary to ensure the students understand the concepts being taught. 
The second problem is that e-learning models are commonly designed for sighted students and do not incorporate considerations for students with disabilities, particularly vision disabilities. Learning outcomes commonly assume that all students are sighted and vision impaired students are expected to attain the same learning outcomes to succeed in the course. More specific and broader communications are required in an e-learning environment for the vision impaired. Without vision, students and teachers use speech to a much greater extent and a virtual classroom is needed to supplement the physical classroom and laboratory setting. There are major differences between the needs of vision impaired students and sighted students. Sighted students are able to access images, diagrams and tables and easily interpret these, whereas vision impaired students are not able to access these at all. E-learning materials are not frequently designed to integrate with the range of assistive technologies used, resulting in vision impaired students receiving incomplete or inaccurate translations, or, at worst, no accessibility at all.

A further problem is that vision impaired students are often isolated by their disability and e-learning models seldom include considerations of social elements. Vision impaired students need confidence building through the sharing of knowledge and skills. Means of communication on issues including assistive technologies, the technology of the learning environment, learning matters, accessibility and general matters need to be part of the learning environment. Students with a vision disability readily share their knowledge so that the group achieves the learning outcomes, not just the individual. Therefore IT is important, so that students have a ready means of communicating their knowledge within the group.

A final problem to be discussed here is that teachers seldom understand the needs of vision impaired students and the barriers to learning these students face. Teachers need to know how to solve learning problems that relate to vision disabilities; they need to understand not only assistive technologies, but also how to work around inaccessible features of the curriculum and the learning environment.

An understanding of the needs of vision impaired students is an essential component when designing an effective and accessible e-learning environment. However, there are a number of overlapping areas which also need to be investigated and incorporated into a model in order to generate a more holistic approach, and these are reflected in the model described later. 


\section{Learning Models for Accessibility}

One of the most prominently discussed approaches to accessible e-learning is Universal Design (UD). This involves designing instructional materials and learning activities (delivery methods, physical spaces, information resources, technology, personal interactions, assessments) so they are usable by all students without the need for adaption or specialized design (Burgstahler, 2007).Burgstahler also points out that although specific accommodations may be needed for students with disabilities, applying universal design concepts in course planning ensures access to the content is maximized for most students and the need for particular adjustments will be diminished.

A number of e-learning models have been presented for students with disabilities. However, very few of these models are conceptual and holistic. For application into an e-learning environment specifically for vision impaired students, most of the proposed accessibility models need modification or honing in order to have value. There are very few holistic e-learning models that relate to accessibility and disabled students. Seale (2006) also states that there are very few original models, theories and metaphors published in the literature to illustrate or build best practice in accessible e-learning.

Many of the approaches and models to e-learning for the disabled are based upon World Wide Web Consortium's (W3C) Web Content and Accessibility guidelines (WAI, 2004). Whilst the guidelines presented by the Web Accessibility Initiative provide a valuable source of checklists, an approach that relies upon lists of factors for compliance risks a disjointed end product that merely meets the requirements. In an effort to supplement the guidelines, several researchers have used these as a foundation for building further theories and/or tools. Daniels and Elliott (2003) present a set of generic guidelines and processes for testing the accessibility of e-learning Web sites, based upon an earlier version of the W3C Web Content Accessibility Guidelines in addition to the earlier work on usability and mobility by other researchers. The result is a generic set of guidelines and, whilst these guidelines are useful for ensuring e-learning Web sites are more accessible, the analysis has a detailed Web-document focus, does not present a holistic perspective and does not take into account other perspectives and factors.

Lazar (Lazar et al., 2004) presented the Web Accessibility Integration Model on Web site accessibility, based upon the influences of stakeholder perceptions, societal foundations and Web accessibility. Lazar and colleagues argue that societal foundations are inadequate with regard to current levels of accessibility as education curriculum does not include accessibility, although accessibility is a government priority. The stakeholder 
perspectives included are those of the Web developer and client, who are the stakeholders who determine whether the Web site is built for accessibility. They posit that guidelines and tools guide the Web developer and also provide a working definition for Web accessibility. Whilst stakeholder perspectives are essential in the development of all e-learning Websites, this model is not designed for direct application into the design of accessible e-learning environments for students with disabilities.

WAI (2006) presented an accessible e-learning model that is contextual in nature and centers on the aspect of stakeholder involvement. This model comprises accessibility drivers in the form of guidelines, standards and legal requirements, a wide collection of stakeholders in higher education who influence or are influenced by accessibility, and the responses of these stakeholders via processes resulting in e-learning outcomes with some level of accessibility. This model provides a more comprehensive approach to e-learning accessibility, and the focus on the stakeholders and their responses together with the drivers and mediators, enables a much richer understanding of the learning environment under study. Seale's contextualized model is a process model rather than a holistic design framework, with only partial applicability to accessibility for vision impaired students with specific requirements.

The most holistic model for accessibility and e-learning emanates from Kelly, Phipps and Swift (2005). This model is circular in format to illustrate that learning is a holistic activity and cultural, political and social aspects need to be considered. The model also places the learner's needs at the centre of the circle. Kelly and colleagues highlight the need to consider issues of individual requirements, accessibility, usability of e-learning resources, the desired learning outcomes, and local factors including institutional and subject discipline aspects, as well as the technical infrastructure. These factors are placed within consideration of quality assurance where standards and guidelines provide a framework for development. A later model by Kelly, Nevile, Draffan and Fanou (2008) places a variety of student needs into the outer circle, including disabilities, cultural, economic, geographical and social needs. The inner circle contains a collection of learning activities and resources that relate to the learning objectives. This holistic model for Web accessibility for e-learning focuses on accessible learning outcomes rather than accessible resources.

Whilst all these models provide valuable input in the design of specialized e-learning environments for the vision impaired, there is much subjective interpretation when such models are applied in practice. It is difficult in many circumstances to define 
what is included in an object or process and how these interact with each other, as well as how these contribute to achieving the overall goals and objectives. In an effort to identify an effective integration of components appropriate to e-learning environments for the vision impaired, further research was undertaken to study the problems faced by the students due to their disability as well as potential solutions and their 'best fit' into a holistic framework.

\section{RESEARCH METHODOLOGY}

The aim of the research underlying this discussion was to investigate specific problems faced by vision impaired students undertaking IT studies at the tertiary level and to develop a more holistic approach to the design of Web-based learning environments for these students. Data was collected over a two-year period using observation and interviews from students and teachers in two e-learning environments specifically developed for the vision impaired. Approximately 100 students with acute vision disabilities were observed as they worked in the two learning environments and 18 students were interviewed and observed in detail. The interviews included answering a set of questions in addition to discussions of their actions and interactions gathered from the observations.

The learning environments studied were designed to teach varying levels of expertise in technology ranging from standard IT applications through to network administration courses. Students were observed as they worked in both virtual and physical classrooms to identify problems faced by them due to their disability, but also workarounds that the students had to undertake to access learning materials. Also studied were presentation and layout methods that worked for students with vision disabilities. Extensive interviews were held with both vision impaired students and their teachers to identify the problems they faced and the solutions they were able to implement. Several of the teachers were also vision impaired and had an in-depth understanding of the problems faced by the students, providing innovative solutions not considered by the sighted teachers. The objective was to produce a holistic model for e-learning environments for vision impaired students. The models proposed from past research as discussed above provided a foundation, identifying aspects and approaches that are important for universal accessibility as well as effective learning environments specific to vision impaired students. Using the observations and interview data collected from the 
case study environments, a holistic model for an e-learning environment for the vision impaired was gradually developed.

\section{THE VIVID HOLISTIC MODEL}

As a result of the analysis undertaken as part of this research, a new holistic model was developed specifically for e-learning environments for the vision impaired. The model was progressively developed over the term of the research based upon relevant literature and past research in this area. An in-depth study of two e-learning environments for the vision impaired, TruVision and the Cisco Academy for the Vision Impaired, were undertaken and analyses of the observations, questionnaires and interviews of both vision impaired teachers and students, as well as sighted teachers, provided relevant input. The new model, VIVID (Vision Impaired using Virtual IT Discovery) incorporates aspects from past models in differing degrees, and aspects which emerged strongly from the observations and interviews with the vision impaired students and teachers.

The VIVID Model as illustrated in Figure 1 is designed to be integrative, holistic and cyclic in nature in order to provide a comprehensive and coherent representation of the entire socio-technical environment within which the vision impaired learner achieves goals. The VIVID model consists of the following main areas: accessibility standards and guidelines and legal requirements, institutional factors, evaluation feedback and enhancement mechanisms, accessible learning outcomes, learner characteristic considerations, social elements, accessible physical and virtual classrooms, and accessible curriculum and teaching materials. 


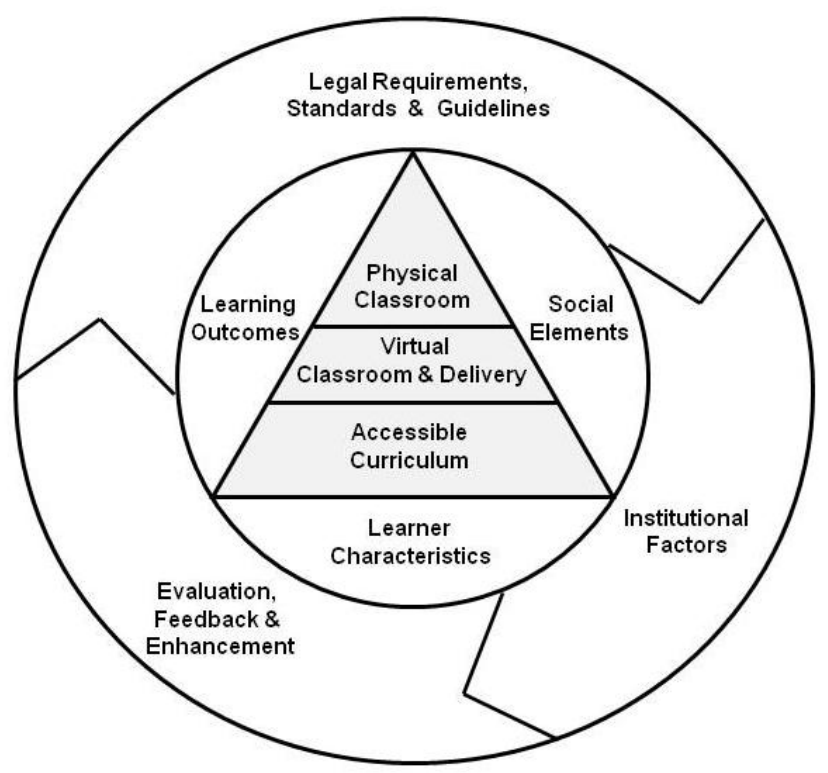

\section{Figure 1 The VIVID (Vision Impaired using Virtual IT Discovery) Model}

The outer circle provides the context and direction, containing the legal requirements, standards and guidelines, factors that relate to the institutional management of the learning environment as well as the means of evaluating not only compliance to these requirements but also providing a mechanism for feedback and enhancement of different parts of the total environment. These factors are usually not within the direct control of those developing and delivering the courses. The inner circle relates to more direct aspects of the learning environment, linking the social, technological, and educational needs and characteristics of the students with the learning materials and their delivery.

\section{Legal Requirements, Standards, and Guidelines}

The standards and guidelines such as the WAI from the $\mathrm{W} 3 \mathrm{C}$ are recognized by government and Web service organizations. Some countries have laws regarding accessibility and non-discrimination policies which guide and drive the requirements for accessibility. Web designers, Web developers and instructional designers should refer to these for the design of learning environments for the vision impaired if accessibility is to be achieved. The developer must choose which laws, standards and guidelines are appropriate for the learning situation at hand and the needs of the disabled students. 
Regular evaluation of standards compliance is also recommended.

\section{- Institutional Factors}

Institutions have their own strategies, policies, regulations and directive processes that will influence the offering and running of educational courses and the environment in which they are delivered. The objectives of the institution will have a bearing upon these factors and will indirectly affect the accessible e-learning environment. Courses in IT for adult vision impaired students could be offered by universities, technical colleges, private colleges, or support organizations that are registered training organizations. The funding models of these institutions will also affect the provision of resources to these courses. Support organizations relying upon donations and grants may not be able to provide an equivalent quality of service and infrastructure such as is provided by a fully government funded organization that specializes in education. Large educational institutions such as universities are likely to have other support structures already in place such as disability services, assistive technologies and learning support mechanisms. Senior Management of the institution will have a bearing upon the activities through decisions made at an institutional level, and these factors must be considered when planning, designing, developing and delivering e-learning education to vision impaired students.

\section{- Evaluation, Feedback, and Enhancement}

In order to maintain an appropriate and accessible IT e-learning environment for the vision impaired, there is a need to ensure that the objectives of the environment continue to be met so that the vision impaired students can achieve the learning outcomes to a predefined level of acceptance. This requires activities to not only evaluate how well the environment is complying with guidelines and standards and achieving in relation to the objectives, but also to provide feedback on all sections of the environment. This enables modifications and enhancements to be put in place to ensure the needs and objectives are met on a continual basis.

\section{Learning Objectives and Outcomes}

Learning outcomes are commonly pre-set by the curriculum and instructional designers, and these often reflect an assumption that students are able-bodied. In standard educational courses these learning outcomes expect the vision impaired students to meet 
the same learning outcomes as sighted students. Learning outcomes in the VIVID model take into account the vision disability of the students, and instructional designers need to be cognizant that although learning objectives will be the same as for sighted students, the learning outcomes may need to be adjusted. An outcome that requires students to perform an action using a specific tool or approach that is inaccessible is not a valid learning outcome in this learning environment. The investigation underlying this research has shown that many learning outcomes focus not on the outcome itself but the method of achieving that outcome. Accessible learning outcomes must reflect what vision impaired students should have achieved as a result of successfully completing accessible IT e-learning courses. Accessible learning outcomes must integrate fully with accessible learning content, delivery and infrastructure in order to present a holistic learning environment. It is important, therefore, that the design of the learning environment is built with accessible learning outcomes as a foundation.

\section{Learner Characteristics}

In order to achieve accessible individual learning experiences, it is necessary to consider the individual's specific needs, background and demographic and cultural factors. The individual's needs with relation to the disability, such as level of vision, the age when the vision impairment occurred (i.e. congenitally blind or blindness through disease), any other medical issues and any other disabilities, will affect needs in a learning environment. Background factors include the individual's age, gender, knowledge and experience of IT, knowledge and experience of the assistive technologies, quality of Internet connection, type and responsiveness of assistive technologies used, acceptance of new technologies and applications, and Web application behaviors in general. Geographic and cultural factors will affect the way the individual connects to the Internet and the applications within the learning environment and the way communication with teachers and other students occurs.

\section{Social Elements}

Social elements refer to the ways in which information can assist the students to communicate, understand, belong, respect and share knowledge as part of a like learning community. Being able to communicate with teachers and other students in a real-time and online environment via a virtual classroom is essential. Applications such as Ventrilo 
can provide a virtual classroom environment where teachers can broadcast lectures, take questions during the broadcast, and encourage learner participation and discussion. Virtual classroom software applications can also enable the students to hear what other students are saying as well as facilitate conversations with teachers. In addition to classroom communications, the vision impaired students need to be able to communicate with other students on a one-to-one or group basis using free communication methods such as e-mail, Skype and social networking sites such as Facebook and MySpace. The building of a group identity is important to vision impaired students who spend the majority of their lives in isolation, either physically on their own, or because of an inability to interact with the environment (people, objects) due to disability. The learning group enables the students to form bonds and develop relationships of trust as they interact together either virtually or in a physical classroom.

\section{- Accessible Curriculum and Teaching Materials}

The learning materials forming the basis of the courses must be fully accessible. While UD principles will provide a sound basis for accessibility, the teaching and learning materials need to be accessible to the vision impaired, and this usually requires additional accessibility considerations. Blind students can almost certainly not access images in many formats (bitmap, JPEG, GIF). Flash diagrams are not translatable by screen readers and many interactive tools are also not identifiable or translatable by assistive technologies. The majority of the problems faced by vision impaired students are related to inaccessible curriculum and teaching materials. The VIVID model incorporates the need for careful consideration and testing to ensure that essential elements are fully accessible. These include teaching materials, practical laboratory exercises, assessments, e-doing tools, games and quizzes, and any additional teaching resources and computerized tools, such as simulations and operating systems.

Vision impaired students also require more time to complete learning tasks and assessments. During this research it was found that blind students require between two and three times the amount of time to complete tasks. This is due to the use of assistive technologies and an inability to see and become familiar with the content and assimilate it to previous knowledge and understanding. 


\section{Accessible Virtual Classroom and Delivery}

Virtual classroom refers to a learning environment where teachers and students are separated by space or time or both, and the teacher provides course content through the use of methods such as course management applications, multimedia resources, the Internet, video recorded lectures, tutorials and case studies. Students receive the content and communicate with the teachers via the same technologies, and skills in using assistive technologies, such as a screen readers or screen magnifiers, are a pre-requisite for vision impaired students who require a sound working knowledge of these tools and their limitations. Designing accessible virtual classroom and delivery mechanisms should include consideration of assistive technologies, vision impaired teachers, Voice over Internet Protocol (VoIP) or equivalent, accessible manuals for virtual classroom operations, sighted teachers to manage the entire environment and assistive technology technicians.

\section{- Accessible Physical Classroom}

In many circumstances, e-learning environments incorporate physical classrooms that support the Web-based learning materials. Even distance learning students with vision impairments require an appropriate physical learning space. The analysis demonstrated that the requirement for an accessible physical classroom for vision impaired students should include considerations to ensure the physical environment is safe and accessible, including appropriate computer desks and workspaces, ergonomic chairs, personal computers and laptops, microphones, printers, electronic USB Whiteboards, accessible teaching aids and an effective and safe classroom layout.

\section{VIVID Model Discussion}

The VIVID model has been developed as a theory building project based upon detailed analyses of two large IT e-learning environments designed specifically for students with severe vision disabilities. The model does not aim to be universally accessible. However, it does include universal accessibility foundations and considerations. The model is yet to be fully applied into a new e-learning environment and such an exercise will undoubtedly highlight changes, additions and enhancements that will add value to the research already carried out. 


\section{CONCLUSION}

The VIVID model described in this paper provides a methodology that maximizes accessibility for the majority of the multitude of disabilities which students may have. VIVID utilizes a holistic approach that overcomes many of the shortcomings of previously developed models and standards while building on the significant contributions previously made. VIVID was developed after extensive consultation and review by key stakeholders, which included a significant number of vision impaired students and teachers. The resultant holistic view of e-learning environments places significant emphasis not only on the technical aspects of accessible design, but also on the importance of inclusion within the learning experience. VIVID provides the necessary tools to create accessible e-learning environments that include complex visual information, interactive activities and simulations. Once the model is fully applied during the development of a new e-learning environment, changes, additions and enhancements will result and these should increase its usability and application.

The cyclic development process specified within the VIVID model is designed to be integrative and reflective of course development, thus allowing modification based on experience. This will result in vision impaired students achieving identical learning outcomes to their sighted peers. A key factor in this is the recognition that a flexible delivery timeline is necessary due to the differing nature of each individual student's disability. Reading speed, cognition and physical access methods (such as vision impaired with upper body motor disability) require variable time lines for completion of tasks so that the identical standard of learning outcomes for sighted students is achieved. Use of this model will facilitate employment and social inclusion through educational programs that include the peer support and networking opportunities currently enjoyed by sighted students in mainstream education.

\section{REFERENCES}

Armstrong, H., Murray, I., \& Permvattana, R. (2010). Web-based learning environments for the vision impaired. In P. Kommers, T. Issa, and P. Isaias (eds.), Proceedings of the IADIS International Conference - Internet Technologies and Society 2010 (pp. 277-281). Perth, WA: IADIS press.

Australian Bureau of Statistics (2009). Disability, ageing and carers, australia: Summary

of findings. Retrieved September 5, 2012, from http://www.abs.gov.au/ausstats/abs@.nsf/mf/4430.0. 
Burgstahler, S. (2007). Universal design of instruction. Retrieved September 5, 2012, from http://www.washington.edu/doit/Brochures/Academics/instruction.html.

Daniels, B., \& Elliott, G. (2003). Developing and applying a generic set of accessibility guidelines to e-learning web sites. In D. Lassnerand and C. McNaught (Eds.), Proceedings of World Conference on Educational Multimedia, Hypermedia and Telecommunications (pp. 3196-3203). Chesapeake, VA: AACE.

Department of Finance and Deregulation (2010). Web accessibility national transition strategy, the Australian government's adoption and implementation of web content accessibility guidelines version 2.0 (WCAG 2.0). Australian Government Information Management Office, Canberra, Australia. Retrieved September 3, 2012 from http://www.finance.gov.au/publications/wcag-2-implementation/.

Kelly, B., Phipps, L., \& Swift, E. (2005). Developing a holistic approach for e-learning accessibility, Canadian Journal of Learning and Technology, 30(3). Retrieved September 3, 2012, from http://www.ukoln.ac.uk/qa-focus/papers/cjtl-2004/.

Kelly, B., Nevile, L., Draffan, E., \& Fanou, S. (2008, May). One World, One Web ... But Great Diversity. Paper presented at the 2008 international cross-disciplinary workshop on Web accessibility (W4A), Beijing, China. Retrieved September 3, 2012, from http://dl.acm.org/citation.cfm?doid=1368044.1368078.

Kelly, P., Sanspree, M., \& Davidson, R. (2000). Vision impairment in children and youth. In Horowitz (Ed.), The lighthouse handbook of vision impairment and vision rehabilitation (pp. 1111-1128). New York : Oxford University Press.

Lazar, J., Dudley-Sponaugle, A., \& Greenidge, K.D. (2004). Improving web accessibility: a study of webmaster perceptions. Computers in Human Behavior, 20(2), 269-288. http://dx.doi.org/10.1016/j.chb.2003.10.018.

Retina Australia (2012). Living with retinal dystrophies: Legal blindness. Retrieved September 5, 2012, from http://www.retinaaustralia.com.au/legal_blindness.htm.

Seale, J. (2006). A contextualised model of accessible e-learning practice in higher education institutions. Australasian Journal of Educational Technology, 22(2), 268-288.

Vision Australia. (2007). Research into employment levels in australia for people who are blind or have low vision. Retrieved September 5, 2012, from http://www.visionaustralia.org.au/docs/news.../Employment_Details.doc.

WAI (2004). Web content accessibility guidelines 2.0. W3C working draft 19. Retrieved September 5, 2012, from http://www.w3.org/TR/WCAG20/. 
International Journal of Cyber Society and Education 30 